\title{
Systematic review of laser and other light therapy for the management of oral mucositis in cancer patients
}

\author{
Cesar Migliorati • Ian Hewson • Rajesh V. Lalla • Heliton Spindola Antunes • \\ Cherry L. Estilo • Brian Hodgson • Nilza Nelly Fontana Lopes • Mark M. Schubert • \\ Joanne Bowen - Sharon Elad • For the Mucositis Study Group of the Multinational \\ Association of Supportive Care in Cancer/International Society of Oral Oncology (MASCC/ISOO)
}

Received: 21 June 2012 / Accepted: 10 September 2012 /Published online: 22 September 2012

(C) Springer-Verlag 2012

\begin{abstract}
Background The aim of this study was to review the available literature and define clinical practice guidelines for the use of laser and other light therapies for the prevention and treatment of oral mucositis.
\end{abstract}

\section{Migliorati $(\square)$}

Department of Diagnostic Sciences and Oral Medicine, College of Dentistry, University of Tennessee Health Sciences Center,

875 Union Avenue, suite N231,

Memphis, TN 38163, USA

e-mail: migliorati@uthsc.edu

\section{Hewson}

Dental Unit Royal Melbourne Hospital,

Grattan Street, Parkville,

Melbourne 3050, Victoria, Australia

e-mail: ihewson@bigpond.net.au

R. V. Lalla

Section of Oral Medicine,

University of Connecticut Health Center,

263, Farmington Avenue,

Farmington, CT 06030-1605, USA

e-mail: lalla@uchc.edu

\section{H. S. Antunes}

Department of Oral Diagnosis, School of Dentistry,

Universidade do Grande Rio (UNIGRANRIO),

Rio de Janeiro, Brazil

e-mail: hspindola@inca.gov.br

\section{H. S. Antunes}

Instituto Nacional de Câncer (INCA),

Rua André Cavalcante, $\mathrm{n}^{\circ} 37,2^{\circ}$ andar,

Rio de Janeiro CEP-20231-050, Brazil

\section{L. Estilo}

Dental Service, Department of Surgery,

Memorial Sloan-Kettering Cancer Center,

1275 York Avenue,

New York, NY 10065, USA

e-mail: estilo@MSKCC.ORG
Methods A systematic review was conducted by the Mucositis Study Group of the Multinational Association of Supportive Care in Cancer/International Society of Oral Oncology. The body of evidence for each intervention, in each cancer treatment setting, was assigned an evidence level. Based on

\section{B. Hodgson}

Pediatric Dentistry, Department of Developmental Sciences,

Marquette University School of Dentistry,

1801 W. Wisconsin Ave.,

Milwaukee, WI 53233, USA

e-mail: brian.hodgson@marquette.edu

\section{N. N. F. Lopes}

Rua Padre Priuli 11,

São Paulo, São Paulo, Brazil

e-mail: nnflopes@terra.com.br

\section{M. Schubert}

Oral Medicine,

UW School of Dentistry, Seattle Cancer Care Alliance,

825 Eastlake Avenue E,

Seattle, WA 98109, USA

e-mail: mschuber@seattlecca.org

J. Bowen

School of Medical Sciences, The University of Adelaide,

Frome Road,

Adelaide, South Australia 5005, Australia

e-mail: joanne.bowen@adelaide.edu.au

\section{S. Elad}

Division of Oral Medicine, Eastman Institute for Oral Health,

University of Rochester Medical Center,

625 Elmwood Ave.,

Rochester, NY 14620, USA

e-mail: SElad@URMC.Rochester.edu 
the evidence level, one of the following three guideline determinations was possible: recommendation, suggestion, and no guideline possible.

Results A new recommendation was made for low-level laser (wavelength at $650 \mathrm{~nm}$, power of $40 \mathrm{~mW}$, and each square centimeter treated with the required time to a tissue energy dose of $2 \mathrm{~J} / \mathrm{cm}^{2}(2 \mathrm{~s} /$ point $)$ ) for the prevention of oral mucositis in adult patients receiving hematopoietic stem cell transplantation conditioned with high-dose chemotherapy, with or without total body irradiation. A new suggestion was made for low-level laser (wavelength around $632.8 \mathrm{~nm}$ ) for the prevention of oral mucositis in patients undergoing radiotherapy, without concomitant chemotherapy, for head and neck cancer. No guideline was possible in other populations and for other light sources due to insufficient evidence.

Conclusions The increasing evidence in favor of low-level laser therapy allowed for the development of two new guidelines supporting this modality in the populations listed above. Evidence for other populations was also generally encouraging over a range of wavelengths and intensities. However, additional well-designed research is needed to evaluate the efficacy of laser and other light therapies in various cancer treatment settings.

Keywords Oral mucositis - Stomatitis · Laser therapy · LLLT - LED · Oral complications of cancer therapy · Mucositis prevention $\cdot$ Mucositis treatment

\section{Introduction}

This manuscript is part of a collaborative effort of the Mucositis Study Group of the Multinational Association of Supportive Care in Cancer (MASCC) and the International Society of Oral Oncology (ISOO) to update the existing guidelines for the prevention and treatment of oral mucositis $(\mathrm{OM})$ in cancer patients. The original and last update of the guidelines in 2004 and 2007, respectively [1, 2], reviewed the various therapies for mucositis, including the use of lowlevel laser therapy (LLLT) [3].

It is known that radiation at certain wavelengths can be beneficial to cells and tissues [4], but there is uncertainty on how this happens. Phototherapy, including LLLT, is based on the interaction of light at low-energy density, a few joules per square centimeter, with cells and tissues without the generation of thermal effects. This type of therapy is believed to promote photochemical, photophysical, and photobiological effects in cells and tissues, without causing temperature rise above $98^{\circ} \mathrm{F}$. It is believed that the biomodulation effect on cells and tissues occurs due to the absorption of the light energy by endogenous photoreceptors [4]. In 1989, a review of several in vitro studies [5] revealed that primary photoactivated receptors are components of the cellular respiratory chain. The activation of these receptors could lead to the stimulation or inhibition of the cellular metabolism, depending on the energy dose of light. Lowenergy doses could regulate the production of reactive oxygen species. Visible light can lead to photochemical changes in the photoreceptors in the mitochondria, altering cell metabolism and producing a transduction effect in other cell components (biomodulation effect) [5]. Others suggest that this effect is due to photophysical changes on the $\mathrm{Ca}++$ channels in the cell membrane [6]. Studies in animal models of oral mucositis have demonstrated that LLLT can promote wound healing as well as have an anti-inflammatory effect, evidenced by a reduction in neutrophil infiltrate and cyclooxygenase-2 expression [7, 8].

Several laser parameters that could alter tissue biology include wavelength (in nanometer), power (in milliwatt), amount of energy delivered to the tissues (in joules per square centimeter), time (in seconds), and the rate of energy delivered into tissues (in milliwatts per square centimeter) [9]. The use of these laser parameters has to be adjusted based on the biological process one is aiming to modulate. Oral mucositis is a complex pathobiological process that involves several epithelial and subepithelial tissue interactions with chemotherapy agents and/or radiation therapy [10]. Thus, the goal is to determine how to best utilize laser parameters to obtain the best biomodulation of tissue reactions.

At the time of the last mucositis guidelines review by the Mucositis Study Group of MASCC/ISOO [3], studies testing laser therapy were few. The panel noted that LLLT requires expensive equipment and specialized training. Because of inter-operator variability, clinical trials are difficult to conduct, and their results are difficult to compare; nevertheless, the panel was encouraged by the accumulating evidence in support of LLLT and suggested that, for centers able to support the necessary technology and training, LLLT be used to attempt to reduce the incidence of oral mucositis and its associated pain in patients receiving high-dose chemotherapy or chemoradiotherapy before hematopoietic stem cell transplant (HSCT).

As part of a comprehensive update of the MASCC/ISOO clinical practice guidelines for mucositis, the aim of this project was to systematically review the available literature and define evidence-based clinical practice guidelines for the use of laser and other light therapy devices for the prevention and treatment of $\mathrm{OM}$.

\section{Methods}

The methods used in this systematic review are described in detail in Bowen et al. and Elad et al., elsewhere in this issue. 
Briefly, a literature search for relevant papers indexed before 31 December 2010 was conducted using OVID/MEDLINE, with papers selected for review based on defined inclusion and exclusion criteria.

Selected papers were reviewed by two independent expert reviewers and data were extracted using a standard electronic form. Studies were scored for their level of evidence based on Somerfield criteria [11] and flaws were listed according to Hadorn criteria [12]. A well-designed study was defined as a study with no major flaws per the Hadorn criteria [12].

Findings from the reviewed studies were integrated into guidelines based on the overall level of evidence for laser and other light therapy agents. Guidelines were classified into three types: recommendation, suggestion, and no guideline possible. Guidelines were separated based on (1) the aim of the intervention (prevention or treatment of mucositis), (2) the treatment modality (radiotherapy, chemotherapy, chemoradiotherapy, or high-dose conditioning therapy for hematopoietic stem cell transplant), and (3) the route of administration of the intervention, when applicable.

The list of intervention keywords used for the literature search of this section included oral mucositis or stomatitis AND lasers, laser, LLLT, low level laser therapy, light therapy, phototherapy, low-level laser, LED, light-emitting diode, diode, visible light, $\mathrm{He}-\mathrm{Ne}$, InGaAlP, GaAlAs, InGaAs, CO2, and infra-red.

\section{Results}

The literature search identified a total of 692 papers from which a total of 24 clinical trials were included for final review [9, 13-35]. The literature review process can be seen in Fig. 1.

Oral mucositis in patients undergoing hematopoietic stem cell transplant, with or without total body irradiation

A recommendation was possible for laser therapy in the wavelength around $650 \mathrm{~nm}$, the intensity of $40 \mathrm{~mW}$, and each square centimeter treated with the required time to a tissue energy dose of $2 \mathrm{~J} / \mathrm{cm}^{2}$ ( $2 \mathrm{~s} /$ point; personal communication) for the prevention of oral mucositis in HSCT. This guideline is based on the combination of one well-designed randomized clinical trial with no major flaws [9] together with a series of studies reporting positive results with laser in a similar range of wavelength which were classified at a lower level of evidence.

The pivotal trial evaluated the efficacy of two different low-level gallium aluminum arsenide diode lasers, 650 and $780 \mathrm{~nm}$ wavelengths in the prevention of oral mucositis in HSCT patients conditioned with chemotherapy or chemoradiotherapy [9]. Patients with clinically normal oral mucosa

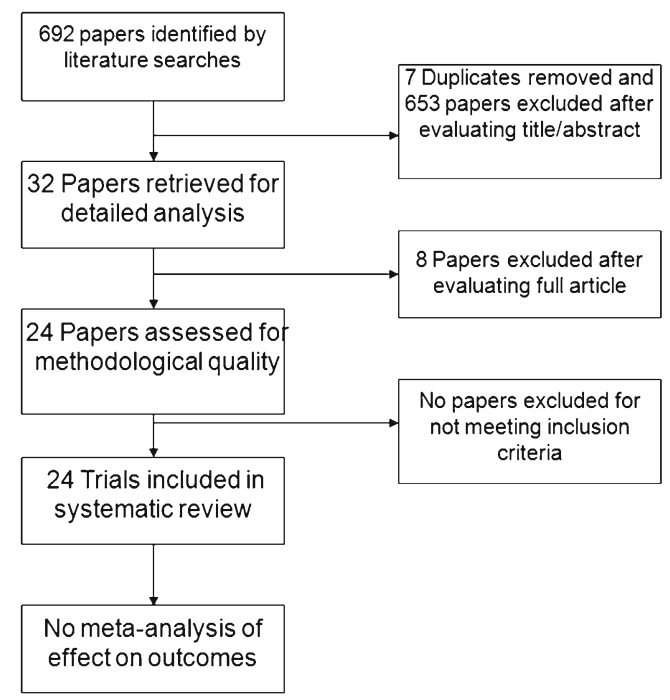

Fig. 1 Literature search: Flow of papers from initial identification through final selection for review

received intraoral laser irradiation in several areas of the mucosa, with energy densities of $2 \mathrm{~J} / \mathrm{cm}^{2}$. Because of the preventive nature of the study, laser treatment began on the first day of the conditioning and continued through day +2 post-HSCT. It was observed that the severity of OM score in patients treated with the $650-\mathrm{nm}$ laser was reduced, compared with placebo and the 780-nm laser groups $(p=0.06)$. Of importance is the fact that patients in the $650-\mathrm{nm}$ group statistically significantly likely received total body irradiation (TBI) thus a more aggressive therapy protocol. An adjusted statistical test for TBI showed that the difference in mucositis severity on day 11 post-HSCT was statistically significant $(p=0.03)$. Laser therapy was well-tolerated and no adverse events developed.

In contrast to the above-mentioned guideline, no guideline was possible for laser as a treatment of OM in HSCT patients. Two studies with mixed cancer populations $[20,21]$ were insufficient to allow for any guideline.

Two non-laser light-therapy devices were reported in the literature for the prevention of OM in HSCT patient population: light-emitting diode (LED) and broad band visible light therapy $[21,22]$. As to LED, there are accumulating data showing that there is no difference in the interaction of a laser and a LED with the human tissue [36-40]. These studies showed positive effects in prevention and treatment of oral mucositis but represent initial investigations of new light technologies, and with the available information no guideline was possible.

\section{Radiotherapy-induced OM}

A suggestion was possible for laser therapy in the prevention of $\mathrm{OM}$ in patients undergoing radiotherapy, without 
concomitant chemotherapy, for head and neck cancer. This guideline is based on three studies showing positive results with laser therapy in the wavelength of $632 \mathrm{~nm}$ [24-26]. However, all three studies had major flaws per the Hadorn criteria, which did not allow for a recommendation.

\section{Radiochemotherapy-induced OM}

No guideline was possible for laser therapy in the prevention or treatment of oral mucositis in patients treated with a combined protocol of radiochemotherapy for head and neck cancer. Studies were inconsistent in demonstrating the effectiveness of laser therapy in this population [27-29]. In addition, major flaws in study design reduced the overall level of evidence to IV.

\section{Chemotherapy-induced oral mucositis}

Studies examining the effects of laser therapy in this population generally reported positive results. However, due to a low overall level of evidence (IV) and varying laser parameters, no guideline was possible for this category either for the prevention or treatment of mucositis using laser therapy or LED.

\section{Discussion}

This systematic review confirmed that the number of clinical trials assessing the use of laser therapy in the prevention and treatment of oral mucositis is growing. It is important to keep in mind that the data presented in this review result from the use of a variety of low-level laser and other light devices that operate in different wavelengths and are applied to tissues using a variety of protocols. Most devices were within the range considered to be low-level laser (10 $200 \mathrm{~mW}$ ) (Table 1). Laser application protocols vary greatly and, therefore, conclusions cannot be applied separately for each of the individual laser devices.

Based on the current scientific information, the panel was able to reach the following decision: "The panel recommends that, for centers able to support the necessary technology and training, LLLT be used to prevent oral mucositis, in HSCT patients receiving high-dose chemotherapy with or without TBI." The best evidence supports the following protocol: $650 \mathrm{~nm}$, with the intensity of $40 \mathrm{~mW}$, and each square centimeter treated with the required time to a tissue energy dose of $2 \mathrm{~J} / \mathrm{cm}^{2}(2 \mathrm{~s} /$ point $)$ to the oral mucosa [9]. This represents a significant change from our previous guidelines in which the use of laser therapy was only a suggestion in HSCT patients. At that time, it had been determined that new evidence from additional randomized trials was necessary before a recommendation could be made $[1,2]$. This new recommendation reflects the growing interest in the use of these devices in oral mucositis.

Our findings are generally consistent with two Cochrane meta-analyses that evaluated the prevention and treatment of oral mucositis with LLLT. The Cochrane prevention metaanalysis [41] analyzed two studies [16, 18] that together showed an $80 \%$ reduction in the incidence of severe mucositis in HSCT. It concluded that overall there is weak evidence from two small studies at some risk of bias that lowenergy laser application may be beneficial in preventing severe mucositis. In addition, the Cochrane treatment meta-analysis [42] analyzed two additional studies [20, 23] with a combined statistically significant benefit for LLLT in oral mucositis in mostly HSCT patients [12]. It concluded that there is limited evidence from two small trials that lowlevel laser treatment reduces the severity of mucositis.

As a suggestion for future research in the field of $\mathrm{OM}$, several aspects of research design should be considered.

- Information already known about laser parameters that is effective should be taken into account. Future studies should examine the effect of altering these laser parameters in different patient populations.

- Major flaws should be avoided when designing a new study (for example, see the Hadorn criteria [12]). Some of the major flaws observed in the studies reviewed in the present study included lack of a well-defined randomization, not using a placebo group, no doubleblinding of both the investigator and the patient, a clear definition of possible confounders that could affect the response to laser therapy, and not using a valid tool for mucositis grading. In addition, laser parameters used were often incompletely described, which limits reproducibility.

- Consider further assessing the effects of phototherapy in an animal model of OM with a focus on elements in the pathobiological process of OM.

- Oral mucositis affects various tissue layers (surface epithelium and subepithelial). Since laser wavelength can affect depth of tissue penetrance, perhaps the combined use of both short and long wavelengths could provide a synergistic effect on mucositis outcomes.

- The newly available blue LED has potential for the management of OM, and research is warranted based on the known effects of this light therapy in wound healing [43].

To emphasize the growing body of evidence in favor of LLLT in OM, several relevant late-breaking publications have been added to the laser-oral mucositis literature since the time we completed the literature search in December 2010. A systematic review with meta-analysis concluded that there is consistent evidence from small high-quality studies (mostly also included in the present review) that 


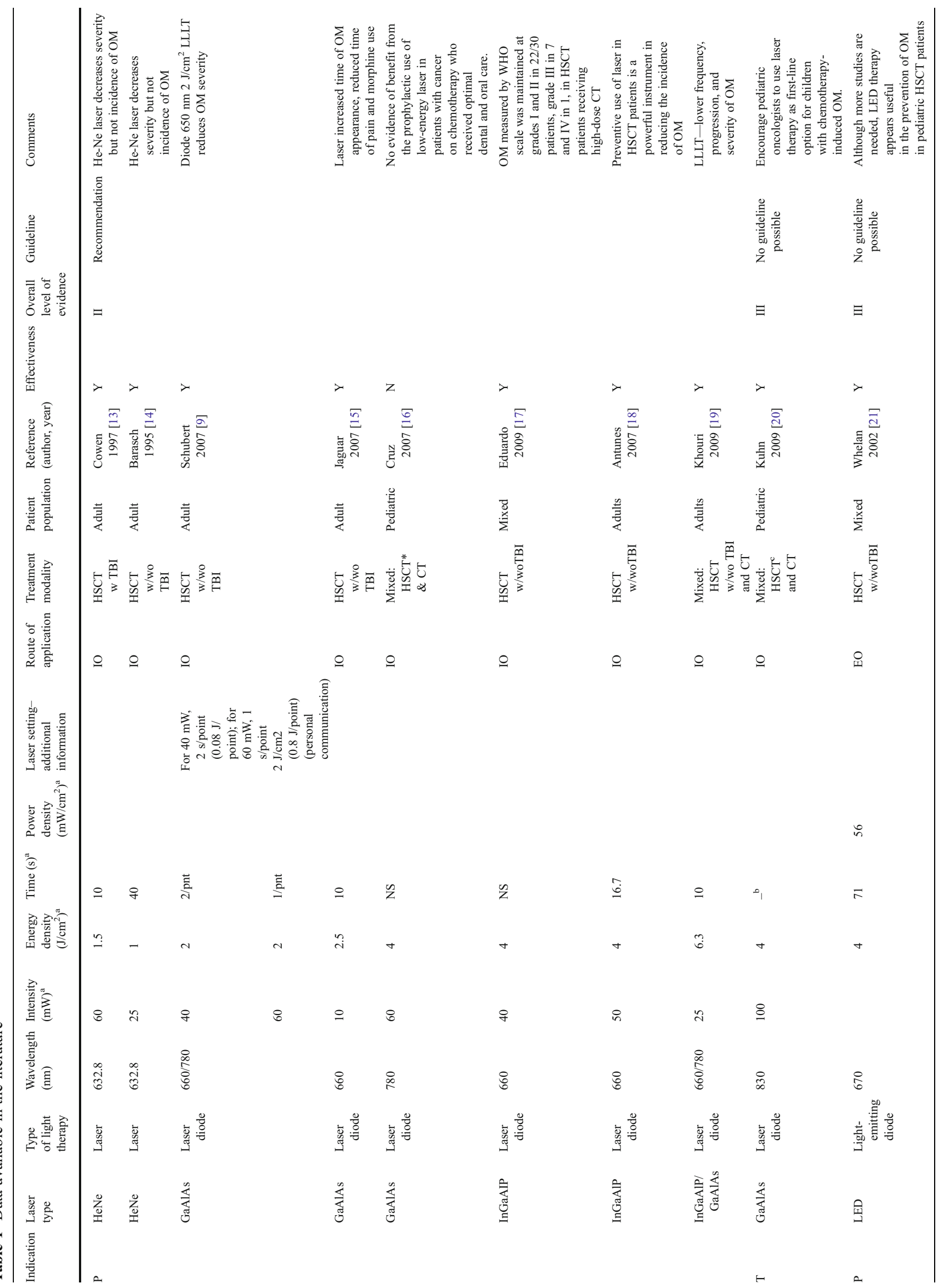




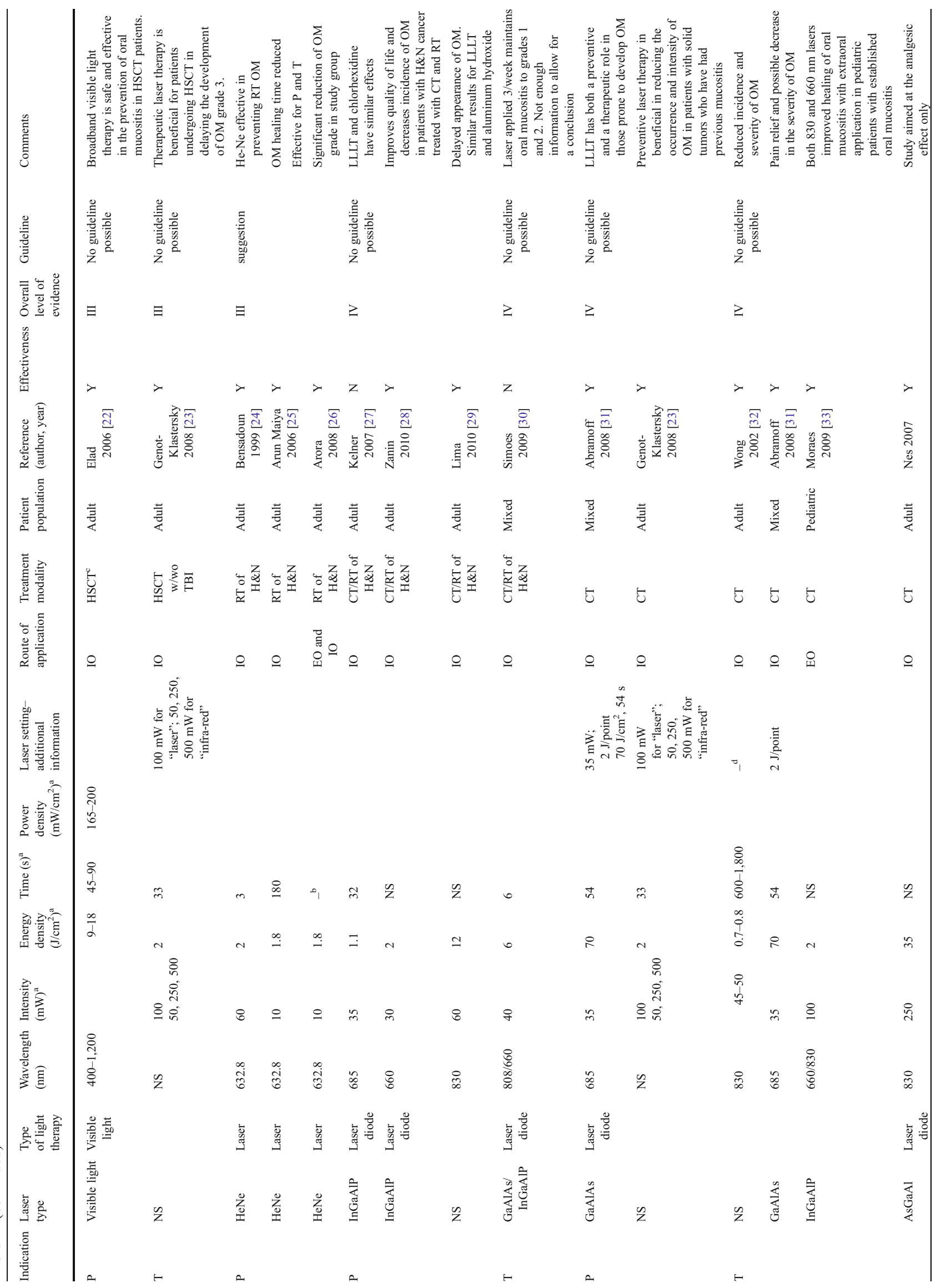


red and infrared LLLT can partly prevent development of cancer therapy-induced OM. It indicated that LLLT significantly reduces pain, severity, and duration of symptoms in patients with OM [44]. Additional data from a trial with near-infrared light-emitting diodes applied extraorally in children and adults with hematological malignancies and solid tumors treated with HSCT demonstrated that the technology can significantly reduce patient-reported pain [45]. A recent randomized study in patients with malignancies treated with HSCT confirmed that oral mucositis incidence and severity can be reduced with LLLT [46].

Late-breaking studies also showed positive outcomes on the prevention and treatment of oral mucositis in head and neck cancer populations being treated with radiation therapy [47], and in prevention of oral mucositis in head and neck cancer populations being treated with concurrent chemoradiation, indicating that this technology seems to be effective in controlling the appearance and severity of OM, its associated pain, and it can also have beneficial effects on quality of life [46, 48, 49].

Because of the variety of laser devices and the variation in individual protocols of laser and other light applications in oral mucositis, it is important to keep in mind that the results of each individual study apply exclusively to the cancer population studied, the wavelength of the laser device, and the settings utilized in that particular study. One additional issue that might play a role in the appearance and duration of $\mathrm{OM}$ is the absolute neutropenia observed in cancer populations treated with myelosuppressive therapies [50]. This confounder has not been evaluated in the majority of the trials and should be included in future investigations of the applicability of LLLT in OM prevention, treatment, and associated pain.

The mechanisms by which lasers promote beneficial effects in OM are not well understood and extrapolated from experimental models. For instance, lasers are forms of coherent light emission. New technologies like LEDs and other non-coherent light waves can also be absorbed by tissue chromophores and promote biological effects. From the data available in the literature (Table 1), it seems that all effective light therapy devices work in similar wavelength bands concentrating around peaks in 650,780 , and $830 \mathrm{~nm}$. The 650- and 780-nm lasers fall within the "red" range and the 830 -nm laser falls within the "near infra-red" range. It is uncertain to what extent the difference in the wavelength of the laser devices is meaningful in terms of light-tissue interaction. Small difference in wavelength, for example 650 vs. $632.8 \mathrm{~nm}$ may have negligible impact on the clinical outcome; however, larger differences may have a clinical impact (for example 650 vs. $780 \mathrm{~nm}$ ). In Schubert et al. [9], the wavelength of $650-\mathrm{nm}$ laser produced better clinical results in the prevention of oral mucositis than the 780-nm laser. Although there is now evidence in the literature 
suggesting that lasers with wavelengths varying between 632 and $830 \mathrm{~nm}$ can have beneficial effects on preventing and treating oral mucositis, no specific protocols that investigated other parameters such as tissue fluency (energy density), ideal time of laser application, variations in cancer type, and cancer treatment regimens are available. It should be noted that there are no studies assessing the effectiveness of laser or other type of light source in any light range except for the red or near-infrared range.

With the advancement of the technology, the early highpricing laser-emitting devices have been reduced considerably, making the technology readily available. Education and training of staff is another factor that must be considered when using LLLT. Most of the protocols studied require daily and long applications. However, based on the accumulating evidence, LLLT has the potential to become a routine practice in the prevention and treatment of oral mucositis and its associated pain

Acknowledgments The authors would like to thank Dr. Rachel Lubart (Department of Chemistry, Bar Ilan University, Ramat Gan, Israel) for consulting on lasers physics.

Disclosure The Mucositis Guidelines Update was sponsored by Helsinn Healthcare S.A, Switzerland and BioAlliance Pharma, France. Per MASCC/ISOO policy, no industry representatives had any role in the development of the guidelines. Sharon Elad has received a research grant from QRay Ltd.

\section{References}

1. Keefe DM (2006) Mucositis guidelines: what have they achieved, and where to from here? Support Care Cancer 14:489-491

2. Rubenstein EB, Peterson DE, Schubert M et al (2004) Clinical practice guidelines for the prevention and treatment of cancer therapy-induced oral and gastrointestinal mucositis. Cancer 100:2026-2046

3. Migliorati CA, Oberle-Edwards L, Schubert M (2006) The role of alternative and natural agents, cryotherapy, and/or laser for management of alimentary mucositis. Support Care Cancer 14:533540

4. Ribeiro M, Zezell DM (2004) Laser de baixa intensidade. In: Gutknecht N, Eduardo CP (eds) A Odontologia e o Laser: Atualizacao do laser na especialidade odontologica, 1st edn. Quintessence, Sao Paulo, pp 217-240

5. Karu T (1989) Photobiology of low-power laser effects. Health Phys 56:691-704

6. Smith K (1991) The pathobiological basis of low level laser radiation therapy. Laser Ther 3:19-24

7. Lopes NN, Plapler H, Chavantes MC, Lalla RV, Yoshimura EM, Alves MT (2009) Cyclooxygenase-2 and vascular endothelial growth factor expression in 5-fluorouracil-induced oral mucositis in hamsters: evaluation of two low-intensity laser protocols. Support Care Cancer 17:1409-1415

8. Lopes NN, Plapler H, Lalla RV et al (2010) Effects of low-level laser therapy on collagen expression and neutrophil infiltrate in 5fluorouracil-induced oral mucositis in hamsters. Lasers Surg Med 42:546-552
9. Schubert MM, Eduardo FP, Guthrie KA et al (2007) A phase III randomized double-blind placebo-controlled clinical trial to determine the efficacy of low level laser therapy for the prevention of oral mucositis in patients undergoing hematopoietic cell transplantation. Support Care Cancer 15:1145-1154

10. Sonis ST, Elting LS, Keefe D et al (2004) Perspectives on cancer therapy-induced mucosal injury: pathogenesis, measurement, epidemiology, and consequences for patients. Cancer 100:1995-2025

11. Somerfield MR, Padberg JP, Pfister DG, Bennett CL, Recht A, Smith TJ, Weeks JC, Winn RJ, Durant JR (2000) ASCO clinical practice guidelines: process, progress, pitfalls, and prospects. Classic Pap Curr Comments 4:881-886

12. Hadorn DC, Baker D, Hodges JS, Hicks N (1996) Rating the quality of evidence for clinical practice guidelines. J Clin Epidemiol 49:749-754

13. Cowen D, Tardieu C, Schubert M et al (1997) Low-energy heliumneon laser in the prevention of oral mucositis in patients undergoing bone marrow transplant: results of a double blind randomized trial. Int J Radiat Oncol Biol Phys 38:697-703

14. Barasch A, Peterson DE, Tanzer JM et al (1995) Helium-neon laser effects on conditioning-induced oral mucositis in bone marrow transplantation patients. Cancer 76:2550-2556

15. Jaguar GC, Prado JD, Nishimoto IN et al (2007) Low-energy laser therapy for prevention of oral mucositis in hematopoietic stem cell transplantation. Oral Dis 13:538-543

16. Cruz LB, Ribeiro AS, Rech A, Rosa LG, Castro CG Jr, Brunetto AL (2007) Influence of low-energy laser in the prevention of oral mucositis in children with cancer receiving chemotherapy. Pediatr Blood Cancer 48:435-440

17. Eduardo FP, Bezinelli L, Luiz AC, Correa L, Vogel C, Eduardo CP (2009) Severity of oral mucositis in patients undergoing hematopoietic cell transplantation and an oral laser phototherapy protocol: a survey of 30 patients. Photomed Laser Surg 27:137-144

18. Antunes HS, de Azevedo AM, da Silva Bouzas LF et al (2007) Low-power laser in the prevention of induced oral mucositis in bone marrow transplantation patients: a randomized trial. Blood 109:2250-2255

19. Khouri VY, Stracieri AB, Rodrigues MC et al (2009) Use of therapeutic laser for prevention and treatment of oral mucositis. Braz Dent J 20:215-220

20. Kuhn A, Porto FA, Miraglia P, Brunetto AL (2009) Low-level infrared laser therapy in chemotherapy-induced oral mucositis: a randomized placebo-controlled trial in children. J Pediatr Hematol Oncol 31:33-37

21. Whelan HT, Connelly JF, Hodgson BD et al (2002) NASA lightemitting diodes for the prevention of oral mucositis in pediatric bone marrow transplant patients. J Clin Laser Med Surg 20:319324

22. Elad S, Ackerstein A, Bitan M et al (2006) A prospective, doubleblind phase II study evaluating the safety and efficacy of a topical histamine gel for the prophylaxis of oral mucositis in patients post hematopoietic stem cell transplantation. Bone Marrow Transplant 37:757-762

23. Genot-Klastersky MT, Klastersky J, Awada F et al (2008) The use of low-energy laser (LEL) for the prevention of chemotherapyand/or radiotherapy-induced oral mucositis in cancer patients: results from two prospective studies. Support Care Cancer 16:1381-1387

24. Bensadoun RJ, Franquin JC, Ciais G et al (1999) Low-energy He/ $\mathrm{Ne}$ laser in the prevention of radiation-induced mucositis. A multicenter phase III randomized study in patients with head and neck cancer. Support Care Cancer 7:244-252

25. Arun Maiya G, Sagar MS, Fernandes D (2006) Effect of low level helium-neon $(\mathrm{He}-\mathrm{Ne})$ laser therapy in the prevention \& treatment of radiation induced mucositis in head \& neck cancer patients. Indian J Med Res 124:399-402 
26. Arora H, Pai KM, Maiya A, Vidyasagar MS, Rajeev A (2008) Efficacy of He-Ne laser in the prevention and treatment of radiotherapy-induced oral mucositis in oral cancer patients. Oral Surg Oral Med Oral Pathol Oral Radiol Endod 105:180-186, 6 e1

27. Kelner N, de Castro JF (2007) Low energy laser in prevention of oral mucositis in patients receiving radiotherapy and/or chemotherapy in Pernambuco cancer hospital. Applied Cancer Res 27:182-187

28. Zanin T, Zanin F, Carvalhosa AA et al (2010) Use of 660-nm diode laser in the prevention and treatment of human oral mucositis induced by radiotherapy and chemotherapy. Photomed Laser Surg 28:233-237

29. Lima AG, Antequera R, Peres MP, Snitcosky IM, Federico MH, Villar RC (2010) Efficacy of low-level laser therapy and aluminum hydroxide in patients with chemotherapy and radiotherapyinduced oral mucositis. Braz Dent J 21:186-192

30. Simoes A, Eduardo FP, Luiz AC et al (2009) Laser phototherapy as topical prophylaxis against head and neck cancer radiotherapyinduced oral mucositis: comparison between low and high/low power lasers. Lasers Surg Med 41:264-270

31. Abramoff MM, Lopes NN, Lopes LA et al (2008) Low-level laser therapy in the prevention and treatment of chemotherapy-induced oral mucositis in young patients. Photomed Laser Surg 26:393400

32. Wong SF, Wilder-Smith P (2002) Pilot study of laser effects on oral mucositis in patients receiving chemotherapy. Cancer J 8:247-254

33. Moraes JJC, Queiroga AS, De Biase RCCG, Leite EP, Cabral Junior CR, Limeira Junior FA (2009) The effect of low level laser therapy in different wavelengths in the treatment of oral mucositisporposal for extra-oral implementation. Laser Physics 19:1-8

34. Corti L, Chiarion-Sileni V, Aversa S et al (2006) Treatment of chemotherapy-induced oral mucositis with light-emitting diode. Photomed Laser Surg 24:207-213

35. Sandoval RL, Koga DH, Buloto LS, Suzuki R, Dib LL (2003) Management of chemo- and radiotherapy induced oral mucositis with low-energy laser: initial results of A.C. Camargo Hospital. J Appl Oral Sci 11:337-341

36. Dall Agnol MA, Nicolau RA, de Lima CJ, Munin E (2009) Comparative analysis of coherent light action (laser) versus noncoherent light (light-emitting diode) for tissue repair in diabetic rats. Lasers Med Sci 24:909-916

37. Vinck EM, Cagnie BJ, Cornelissen MJ, Declercq HA, Cambier DC (2003) Increased fibroblast proliferation induced by light emitting diode and low power laser irradiation. Lasers Med Sci 18:95-99

38. Corazza AV, Jorge J, Kurachi C, Bagnato VS (2007) Photobiomodulation on the angiogenesis of skin wounds in rats using different light sources. Photomed Laser Surg 25:102-106
39. Fixler D, Ankri R, Duadi H, Lubart R, Zalevsky Z (2012) Depolarization of light in biological tissues. Opt Lasers Eng 50:850-854

40. Fixler D, Duadi H, Ankri R, Zalevsky Z (2011) Determination of coherence length in biological tissues. Lasers Surg Med 43:339343

41. Worthington HV, Clarkson JE, Bryan G, et al. Interventions for preventing oral mucositis for patients with cancer receiving treatment. Cochrane Database Syst Rev 2011:CD000978

42. Clarkson JE, Worthington HV, Furness S, McCabe M, Khalid T, Meyer S. Interventions for treating oral mucositis for patients with cancer receiving treatment. Cochrane Database Syst Rev 2010: CD001973

43. Adamskaya N, Dungel P, Mittermayr R et al (2011) Light therapy by blue LED improves wound healing in an excision model in rats. Injury 42:917-921

44. Bjordal JM, Bensadoun RJ, Tuner J, Frigo L, Gjerde K, LopesMartins RA (2011) A systematic review with meta-analysis of the effect of low-level laser therapy (LLLT) in cancer therapy-induced oral mucositis. Support Care Cancer 19:1069-1077

45. Hodgson BD, Margolis DM, Salzman DE et al (2012) Amelioration of oral mucositis pain by NASA near-infrared light-emitting diodes in bone marrow transplant patients. Support Care Cancer 20 (7): $1405-1415$

46. Silva GB, Mendonca EF, Bariani C, Antunes HS, Silva MA (2011) The prevention of induced oral mucositis with low-level laser therapy in bone marrow transplantation patients: a randomized clinical trial. Photomed Laser Surg 29:27-31

47. Carvalho PA, Jaguar GC, Pellizzon AC, Prado JD, Lopes RN, Alves FA (2011) Evaluation of low-level laser therapy in the prevention and treatment of radiation-induced mucositis: a double-blind randomized study in head and neck cancer patients. Oral Oncol 47(12):1176-1181

48. Antunes HSHD, Araujo CM, Cabral E, Ferreira EM, Small IA et al (2011) Phase III trial of low-level laser therapy to prevent induced oral mucositis in head and neck cancer patients submitted to concurrent chemoradiation. J Clin Oncol 29:2011 (suppl; abstr LBA5524)

49. Gouvea de Lima A, Villar RC, De Castro G Jr et al (2012) Oral mucositis prevention by low-level laser therapy in head-and-neck cancer patients undergoing concurrent chemoradiotherapy: a phase III randomized study. Int J Radiat Oncol Biol Phys 82:270-275

50. McCann S, Schwenkglenks M, Bacon P et al (2009) The Prospective Oral Mucositis Audit: relationship of severe oral mucositis with clinical and medical resource use outcomes in patients receiving high-dose melphalan or BEAM-conditioning chemotherapy and autologous SCT. Bone Marrow Transplant 43:141-147 